\title{
EXPLORATION OF IN VIVO ANTIOXIDANT ACTIVITY OF 50\% ETHANOLIC EXTRACT OF SESAMUM INDICUM L. SEED AGAINST HIGH FAT DIET INDUCED RATS
}

\author{
ZAFAR JAVED KHAN*, NAEEM AHMAD KHAN \\ Department, of Ilmul Advia, Faculty of Unani Medicine, Aligarh Muslim University, Aligarh \\ Email: hkmnaeemkhan@gmail.com
}

Received: 11 Aug 2019, Revised and Accepted: 10 Oct 2019

\begin{abstract}
Objective: The aim of the present study was to investigate the in vivo antioxidant potential of $50 \%$ ethanolic extract of Sesamum indicum against high-fat diet-induced rats.
\end{abstract}

Methods: Animals were treated with plant extract for $30 \mathrm{~d}$, and a high-fat diet was given to all groups except plain control, throughout, out the study. And alpha-tocopherol acetate (Vit, E) was used as standard. Pre-treatment with $16 \mathrm{mg} / 100$ gm of body weight of $50 \%$ ethanolic extract of Sesamum indicum improved the Superoxide dismutase, catalase, glutathione, and lipid peroxidation levels significantly as compared to control group.

Results: The present studies revealed that Sesamum indicum has significant in vivo antioxidant activity and can be used to protect tissue from oxidative stress. The result showed that the activities of SOD, catalase, lipid peroxidase, and glutathione, in the group treated with high-fat diet declined significantly than that of normal group.

Conclusion: 50\% ethanolic extract of in the dose of Sesamum indicum $16 \mathrm{mg} / 100 \mathrm{gm}$ of body weight, has improved the SOD, catalase, glutathione, and lipid peroxidase levels significantly, which were comparable with high-fat-diet-induced rats. Based on this study we conclude that the $50 \%$ ethanolic extract of Sesamum indicum possesses in vivo antioxidant activity and can be employed in protecting tissue from oxidative stress.

Keywords: Sesamum indicum, Alpha-tocopherol, Superoxide dismutase, Antioxidant activity

(c) 2019 The Authors. Published by Innovare Academic Sciences Pvt Ltd. This is an open-access article under the CC BY license (http://creativecommons.org/licenses/by/4.0/) DOI: http://dx.doi.org/10.22159/ijcpr.2019v11i6.36342

\section{INTRODUCTION}

The use of plants in the management and treatment of diseases started with the advent of life. In recent years considerable research has been done on an array of plants having medicinal values. Therefore, the medicinal plants and their therapeutic values are extensively used to cure an array of diseases all over the world. Antioxidants are agents that protect our body against damage by the free radicals such as vit $\mathrm{E}$, vit $C$, etc. which are responsible for combating the diseases caused mainly or partly by oxidative stress. The oxidative stress deregulates a series of cellular functions and lead to various pathological conditions like arthritis, asthma, autoimmune diseases, carcinogenesis, cardiovascular diseases, cataract, diabetes, neurodegenerative diseases and ageing etc. The human body has several mechanisms to counteract oxidative stress, mainly by producing antioxidants. Endogenous and exogenous antioxidants act as "free radical scavengers" by preventing and repairing damages caused by reactive oxygen species (ROS) and reactive nitrogen species (RNS), and therefore, can enhance the immune defense and lower the risk of many, life-threatening diseases [1]. Many plants extracts and products have been shown to have significant antioxidant activity. Therefore, herbal or natural drugs show significant variation in the chemical composition. This can be so drastic as to cause therapy failure or toxicity, so it can be appreciated that different samples of the same natural drug would rather commonly produce significantly different responses. So it is necessary to determine some crucial physicochemical characters of each sample before its pharmacological study to ensure that subsequent study would use the same natural drugs. The antioxidant activity is basically a chemical activity so the chemical nature of antioxidant agents is of much greater importance in the elucidation of their pharmacology. Therefore, along with the pharmacological study for antioxidant activity, the test drugs were also subjected to a physicochemical study. The drug Kunjad Sufaid consists of dried seeds of sesamum indicum Linn. Syn. S. orientale Linn., S. luteum Retz., S. occidentalis [2]. It is commonly known as Til, sesame or benne seed, is cultivated through, out India, mainly for its seeds and oil, in India mainly grown in Mp, Up, Rajasthan, TN, and Maharashtra. This species is often found wild on roadsides and wasteland [3]. An erect annual plant more or less foetid and glandular, the plant is indigenous to tropical Africa and cultivated throughout the warmer parts of India $[4,5]$. It (Sesamum indicum) is one of the oldest cultivated plants in the world, mainly grown for extraction of oil from seeds. And there are three varieties of sesamum seed are found: black, white, and red $[6,7]$. The oil from sesame plant is an important ingredient in Unani remedies in India and is used in Chinese medicine to increase energy and prevent aging ${ }^{8}$ due to the presence of bioactive components present in the seed including polyunsaturated fatty acids, phytosterols, tocopherols, vital minerals and unique class of phenylpropanoid compounds namely lignans such as sesamin, sesamol and sesamolin ${ }^{9}$. These phytochemicals provide defense mechanism against reactive oxygen species and increases keeping quality of oil by preventing oxidative rancidity $[10,11]$. Sesame lignans have various pharmacological properties including, antioxidant activity [12, 13], antimicrobial activity [14] anti-proliferative activity [15] lowering cholesterol levels [16] increasing hepatic fatty acid oxidation enzymes [17] and show antihypertensive effects [18, 19]. Sesame seed has been used as a medicine since antiquity. They are considered to act as aphrodisiac, demulcent, lactogogue, emmenagogue, diuretic, and laxative [4, 20, 21], Sesame is very effective in lowering cholesterol levels due to its lignans content Sesame seeds serve to boost the immune system of the body due to its phytosterol content. It is also believed that Til can help in prevention of certain forms of cancers. Recently, the use of Unani drugs has been increased in various ailments due to the failure of modern medicine, which could not provide effective treatment for chronic diseases, and adverse effects of chemical drugs, and their increasing cost. Moreover, greater public access to information on traditional medicine has increased interest in alternative treatments. Keeping in view of all these facts, the present study is being carried out with the following various parameters.

\section{MATERIALS AND METHODS}

Collection of plant

The seeds of Sesamum indicum (Kunjad) were procured from local market of Aligarh. And are properly identified according to the 
botanical, Unani and Ayurvedic literature and then confirmed in pharmacognosy section of the department of Ilmul Advia. A herbarium sample of the test drugs was prepared and submitted to mawalid-e-salasa museum of the department after identification for further reference, Kunjad, voucher no. SC-0183/15.

\section{Preparation of extracts}

The seeds of Sesamum indicum was cleaned from the earthy material, a shade-dried to powdered, in electrical grinder with slow and light movement to avoid sticking of the drug material with the grinder and after that, the drug was passed through the sieve no. 80 to confirm its fineness and uniformity of particle size. And the powder was packed into soxhlet apparatus and extracted with $50 \%$ ethanol $\left(64.5-65.5^{\circ} \mathrm{C}\right)$. The extract was filtered and concentrated by evaporation on the water bath. The yield percentage was calculated with reference to crude drug and was found to be $14 \%$ for Kunjad.

\section{Preliminary physicochemical and phytochemical screening}

The physicochemical study of the test drugs included the study for Organoleptic characters, ash value, moisture content, $\mathrm{pH}$ value, loss of weight on drying, successive extractive value, alcohol and watersoluble matter, bulk density. The Preliminary phytochemical screening was carried out with different extract of Sesamum indicum pods for the detection of various phytochemicals. Tests for common phytochemicals were carried out by standard methods [22].

\section{Safety study}

The powder of seeds of Sesamum indicum was studied to evaluate the presence of microbial load, pesticide residue, aflatoxins and heavy metals at Delhi Test House, Azadpur, Delhi-110033.

\section{Drugs}

The test drugs were obtained as describe above. Sample of Sesamum indicum was found to be the standard in light of our physicochemical studies; therefore, they used for pharmacological studies. $\alpha$ tocopherol acetate, used as the standard drug, was obtained from Loba chemical. The hydro-alcohlic $50 \%$ alcohol and 50\% water) extract of the drug was used for the study. The yield percentage was calculated with reference to the dried drug. The extract of test drugs was dissolved in distilled water. The dose was obtained by multiplying the Unani clinical dose with an appropriate conversion factor of 7 for rats [22], and found to be $15 \mathrm{mg} / \mathrm{kg}$ BW for $\alpha$ tocopherol acetate, and $16 \mathrm{mg} / 100 \mathrm{gm}$ BW for Sesamum indicum. A feeding canula was used to administer the suspension which was homogenized by shaking well for two minutes.

Diet

Animals during the acclimation period were fed the commercially available rat chow (Ashirwad diet). Afterwards a special high lipid diet/atherogenic diet[23], containing butter (5g), bread slice (1), wheat flour 3 tea spoon), milk powder (1.5 tea spoon), cholesterol powder $(60 \mathrm{mg} / \mathrm{kg})$ and coconut oil $(1 \mathrm{ml})$ was also given during experimentation period along with the normal diet to all the animals except those in plain control. The high lipid diet was given every day in the morning to the animals and when they consumed it they were allowed free access to the normal diet.

\section{Animals}

Male albino rats (Wister strain) of same age, weighing 150-200 gm, were purchase from the central animal house of Indian veterinary research institute Bareilly, Up, India. The animals were housed in sufficiently large cages and treated under humane and hygienic condition with maintained at uniform temperature $25 \pm 2{ }^{\circ} \mathrm{C}$ and $12 \mathrm{~h}$ day: night cycle according to departmental ethical committee for animal experimentation. and were fed on standard diet (Ashirwad industries, Chandigarh, India) and tape water, ad libitum, The animal are deprived of food for $12 \mathrm{~h}$ before the administration of treatment, water was provided throughout the study. The animals in all the groups were administered with the treatment by oral route once a day for $30 \mathrm{~d}$. Before starting the experiment, permission from the Institutional Animal Ethics Committee was obtained, animal experimentations were permitted by Ministry of environment and forests, government of India under registration no. $714 / 02 /$ aCPCSEA. It was issued by committee for the purpose of control and supervision of experiments on animals (CPCSEA) dated $15^{\text {th }}$ September 2016 and approved by the Institutional Animal Ethics Committee (IAEC) of department of biochemistry, Faculty of Life Science, Aligarh Muslim University, Aligarh, India.

\section{Experimental design}

Rats were divided randomly into four groups of six animals each and treated for $30 \mathrm{~d}$ as follows. Group-I animals served as plain control, treated with vehicle (vehicle control). Group-II served as control group treated with high fat diet and normal diet throughout the study. Group-III served as a standard group, and was administered alpha tocopherol acetate in a dose of $15 \mathrm{mg} / \mathrm{kg}$ bw. Group-IV was treated with daily dose of $16 \mathrm{gm} / 100 \mathrm{gm}$, bw. of ethanolic extract of Sesamum indicum for $30 \mathrm{~d}$. High fat diet was given in all groups except in plain control group. $6 \mathrm{~h}$ after the last treatment, on day 31 the rats were anaesthetized by chloroform and sacrificed, all efforts were made to minimize suffering, sacrificed by blood, liver, and brain was rapidly excised, rinsed in ice-cold saline, and a $10 \% \mathrm{w} / \mathrm{v}$ homogenate was prepared using $0.15 \mathrm{M} \mathrm{KCI}$, centrifuged at $800 \mathrm{rpm}$ for $10 \mathrm{~min}$ at $4{ }^{\circ} \mathrm{C}$. The supernatant obtained was used for the estimation of catalase, lipid peroxidase, and other enzymes. Further, the homogenate was centrifuged at $1000 \mathrm{rpm}$ for $20 \mathrm{~min}$ at $4{ }^{\circ} \mathrm{C}$ and the supernatant was used for biochemical estimation.

\section{Collection and preparation of biological samples}

After sacrificing the animals, the blood was collected and centrifuged at $2500 \mathrm{x} \mathrm{g}$ for $10 \mathrm{~min}$ at $4{ }^{\circ} \mathrm{C}$ and the separated serum was collected carefully. The liver and brain were also removed immediately, washed with chilled normal saline and preserved in ice. A $10 \% \mathrm{~W} / \mathrm{V}$ homogenate was prepared in chilled $0.15 \mathrm{M}$ KCL for Lipid Peroxidation, and Superoxide Dismutase; in $0.1 \mathrm{M}$ Chilled Tris Hcl buffer ( $\mathrm{pH}$ 8.2) for Glutathione Reductase, and $50 \mathrm{mmol}$ phosphate buffer for Catalase. The parameter estimated in serum, liver and brain were Lipid peroxidation, Superoxide Dismutase, Catalase, and Glutathione Reductase.

\section{Statistical analysis}

The concentration of each parameter in various animal groups (Gp I-IV) was statistically compared for determining the significance of difference by one-way ANOVA test followed by pair-wise comparison of various groups by LSD. P-value of 0.05 or less was considered significant. The analysis was carried out by using the software of the website, www.myassay.com. Values are presented as mean \pm standard deviation for groups of six animals.

\section{Biochemical estimation}

\section{Estimation of superoxide dismutase (SOD)}

The activity of superoxide dismutase was estimated by Elisa reader with the help of a commercially available Detectx Superoxide Dismutase (SOD) colorimetric activity kit. (K028-H1) Arbor Assays USA.

\section{Principle}

The substrate is added followed by Xanthine oxidase reagent and incubated at room temperature for $20 \mathrm{~min}$. The Xanthine oxidase generates superoxide in the presence of oxygen, which converts a colorless substrate in the detection reagent into a yellow-colored product. The colored product is read at $450 \mathrm{~nm}$. Increasing levels of SOD in the samples causes a decrease in superoxide concentration and reduction in yellow product. The activity of the SOD in the sample is calculated after making a suitable correction for any dilution and expressed in terms of unit of SOD activity per ml.

\section{Estimation of catalase}

The catalase activity was determined by elisa reader with the help of a commercially available Detectx Catalase colorimetric activity kit. (K033-H1) Arbor Assays USA.

\section{Principle}

Samples are diluted in the provided assay buffer and added to the wells of a half area clear plate. Hydrogen peroxide is added to each 
well and the plate incubated at room temperature for 30 minute. The supplied substrate is added, followed by diluted horseradish peroxidise and incubated at room temperature for $15 \mathrm{~min}$. The HRP reacts with the substrate in the presence of hydrogen peroxide to convert the colorless substrate into a pink-colored product. The colored product is read at $560 \mathrm{~nm}$. Increasing levels of catalase in the samples causes a decrease in $\mathrm{H}_{2} \mathrm{O}_{2}$ concentration and reduction in pink product, and expressed in terms of units of Catalase activity per ml.

\section{Estimation of lipid peroxidation (TBARS)}

Lipid peroxidation was estimated by Elisa reader with the help of commercially available Quantichrom TM TBARS Assay kit (DTBA100), Bioassay Systems USA.

\section{Principle}

Bioassay system' TBARS assay is based on the reaction of TBARS with thiobarbitturic acid (TBA) to form a pink colored product. The color intensity at $535 \mathrm{~nm}$ or fluorescence intensity at $(\lambda \mathrm{ex} / \mathrm{em}=560$ $\mathrm{nm} / 585 \mathrm{~nm}$ ) is directly proportional to TBARS concentration in the sample, and expressed in terms of $\mu \mathrm{M}$ MDA $(\mu \mathrm{M}=\mu \mathrm{mole} / \mathrm{liter}=\mathrm{nmole} / \mathrm{ml})$.

\section{Estimation of glutathione reductase (GR)}

The Glutathione reductase activity was estimated by elisa reader with the help of commercially available Quantichrom ${ }^{\mathrm{TM}}$ Glutathion Reductase Kit (ECGR-100), Bioassay Systems USA.

\section{Principle}

Bioassay system' non-radioactive, colorimetric GR assay is designed to accurately measure GR activity in biological samples with a method that utilizes Ellaman's method in which DTNB reacts with the GSH generated from the reduction of GSSG by the GR in a sample to form a yellow product $\left(\mathrm{TNB}^{2} \mathrm{-}\right.$. The rate of changes in the optical density, measured at $412 \mathrm{~nm}$, is directly proportional to GR activity in the sample, and expressed in terms of unit per ml, The 1 Unit (U) of GR will catalyze the conversion of $1 \mu$ mole of GSSG to $2 \mu$ mole GSH per min at $\mathrm{pH} 7.6$

\section{Estimation of lipid profile}

\section{Estimation of cholesterol}

Cholesterol was estimated by photocolorimeter with the help of commercially available cholesterol (SR) kit based on CHOD/PAP method, (Erba Mannheim Germany).

\section{Principle}

The estimation of cholesterol involves the following enzyme catalyzed reactions.

$$
\begin{gathered}
\text { Cholesterol ester } \mathrm{CE} \longrightarrow \text { Cholesterol+Fatty acid } \\
\text { Cholesterol }+\mathrm{O}_{2} \mathrm{CHOD} \longrightarrow \text { Cholest-4-en3-one+ } \mathrm{H}_{2} \mathrm{O}_{2} \\
2 \mathrm{H}_{2} \mathrm{O}_{2}+4 \mathrm{AAP}+\text { Phenol POD } \longrightarrow 4 \mathrm{H}_{2} \mathrm{O}+\text { Quinoneimine }
\end{gathered}
$$

\section{Estimation of triglyceride}

Triglyceride was estimated by photocolorimeter with the help of commercially available triglyceride (SR) kit based on GPO/PAP method, (Erba Mannheim Germany).

\section{Principle}

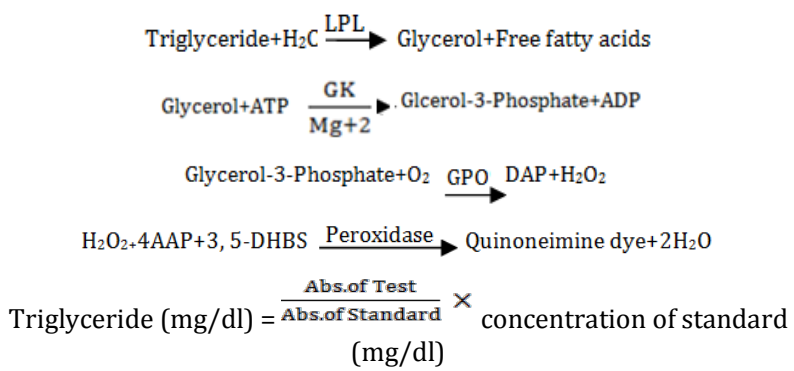

Estimation of HDL cholesterol
HDL cholesterol was estimated by photocolorimeter with the help of commercially available HDL cholesterol PPT. set based on phosphotungstic acid method, (Erba Mannheim Germany).

Principle chylomicrons, LDL and VLDL (low and very low density lipoproteins) are precipitated from serum by phosphotungstate in the presence of divalent cations such as magnesium. The HDL cholesterol remain unaffected in the supernat and is estimated using ERBA cholesterol reagent.

Serum/plasma Phosphotungstate HDL+(LDL+VLDL+Chylomicrons) $\mathrm{Mg}^{2+}$ (Supernatent) (Precipitate).

\section{Abs.of Test}

HDL Cholesterol $(\mathrm{mg} / \mathrm{dl})=\overline{\text { Abs.of Std. }} \times$ concentration of standard $(\mathrm{mg} / \mathrm{dl}) \times$ dilution factor

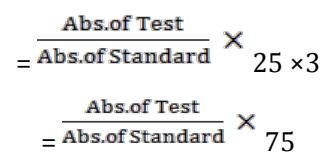

\section{Estimation of LDL and VLDL}

The values of LDL were calculated by following formulae.

LDL $=$ Total cholesterol-HDL-VLDL (Friedewald formulae) VLDL = Triglyceride/5 [24]. The atherogenic index of plasma was calculated by the formula AIP $=[$ TGL/HDL] . While HDL/IDL ratio by dividing the value of HDL with that of LDL.

\section{RESULTS}

The present study determines a comprehensive range of physicochemical characters of the drug according to the parameters used in pharmacopeia, which may serve as the standard for ensuring optimum efficacy and safety of various samples of the drug. In phytochemicals investigation it was found that different extract of Kunjad (Sesamum indicum) contained alkaloids, phenol, carbohydrate, protein, sterols, glycosides, While in safety study it was found that heavy metals (Arsenic, Mercury, Cadmium) were not found to be present, only Lead are present, and microbial load count (Bacterial count 600 and yeast and mould 50) were found which is within permissible limit as per WHO guidelines, while aflatoxins, pesticides and specific pathogen was found to be absent in the crude drug sample, indicating that the drug is free from toxicity.

\section{In vivo antioxidant activity}

The present study was undertaken, to assess the in vivo antioxidant potential of $50 \%$ ethanolic extract of Sesamum indicum against high fat diet induced rats, in serum, liver, and brain homogenate of control and experimental groups of rats. The results showed that the activities of superoxide dismutase (SOD), catalase (CAT), and glutathione reductase (GR) in the liver, brain and serum of control and experimental groups of rats was significantly lower in the high fat diet control group as compared to the plain control group. In the standard group, and Sesamum indicum treated group the activity of these enzymes was significantly, increased in comparison to that in the control group (table 1 to 3 ).

Table 4 shows the activities of lipid peroxidation (TBARS) in the liver, brain and serum of control and experimental groups of rats. The activity of lipid peroxidation (TBARS) in liver, brain and serum was significantly elevated in the high fat diet control group as compared to the plain control group. In the standard group, and Sesamum indicum treated group the activity of (TBARS) was significantly lower in comparison to that in the control group (table 4).

Table 5 shows the activities of lipid Profile in serum of control and experimental groups of rats. The activity of lipid profile in serum was significantly elevated in the high fat diet control group as compared to the plain control group. In the standard group, and Sesamum indicum treated group the activity of lipid profile was significantly lower in comparison to that in the control group (table 5).

The test drugs exhibits high efficacious antioxidant activity. They are shown to be more effective than the standard 
antioxidant agents, the test drugs shown to be comprehensive antioxidant agents as they have been found to be effective in three biological samples, namely liver and brain homogenate and serum.

Table 1: Effect of hydro-alcohlic extract of Kunjad (Sesamum indicum) on the activity of Superoxide dismutase (SOD) in high fat diet induced rats, in serum, liver and brain

\begin{tabular}{llll}
\hline \multicolumn{2}{l}{ Superoxide dismutase (SOD) $(\mathbf{U} / \mathbf{m l}) *$} & & \\
\hline Groups & Serum & Liver & Brain \\
Plain control & $1.05 \pm 0.02$ & $2.81 \pm 0.06$ & $1.71 \pm 0.31$ \\
Control & $0.69 \pm 0.05 \mathrm{~b}^{* * *}$ & $1.79 \pm 0.02 \mathrm{~b}^{* * *}$ & $1.08 \pm 0.00 \mathrm{~b}^{* *}$ \\
Standard & $1.10 \pm 0.07 \mathrm{a}^{* * *} \mathrm{~b}^{*}$ & $2.95 \pm 0.03 \mathrm{a}^{* * *} \mathrm{~b}^{*}$ & $2.17 \pm 0.02 \mathrm{a}^{* * *} \mathrm{~b}^{*}$ \\
Kunjad & $0.87 \pm 0.04 \mathrm{a}^{*}$ & $2.39 \pm 0.09 \mathrm{a}^{* * *}$ & $1.63 \pm 0.06 \mathrm{a}^{* *}$ \\
\hline
\end{tabular}

$(\mathrm{n}=6)$, Values are in mean \pm SEM. Where ${ }^{*} \mathrm{P}<0.05$ and ${ }^{* *} \mathrm{P}<0.01 * * * \mathrm{p}<0.001, \mathrm{a}=$ Against control, $\mathrm{b}=$ Against plain control, $\mathrm{c}=$ Against standard, ${ }^{*}$ The results are expressed in term of unit of SOD activity per ml.

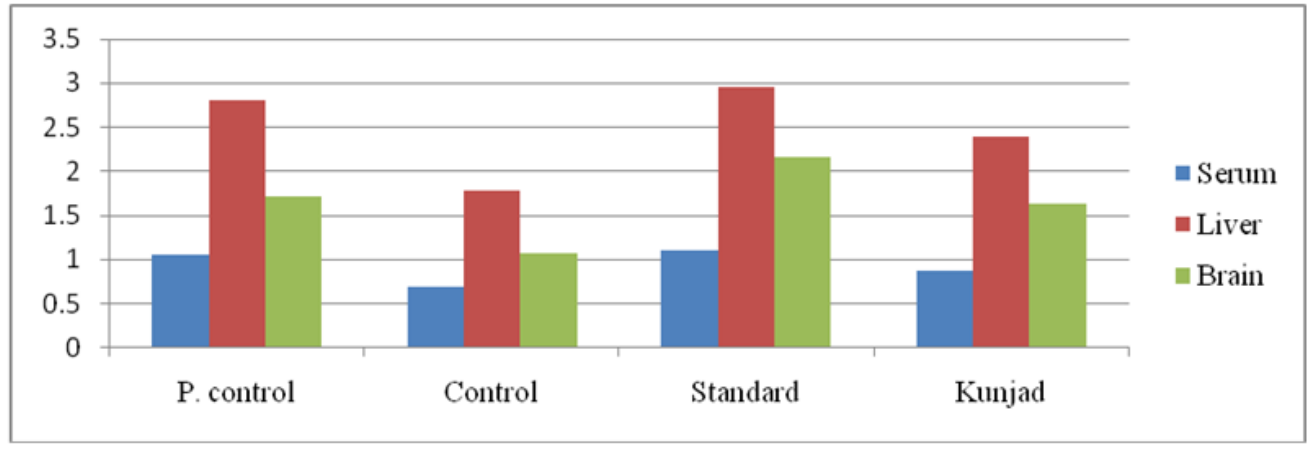

Fig. 1: Activity of superoxide dismutase (SOD) in serum, liver and brain (U/ml)

Table 2: Effect of hydro-alcohlic extract of Kunjad (Sesamum indicum) on the activity of catalase in high fat diet induced rats, in serum, liver and brain

\begin{tabular}{llll}
\hline Catalase (U/ml)* & & & \\
\hline Groups & Serum & Liver & Brain \\
Plain control & $1.18 \pm 0.019$ & $3.41 \pm 0.037$ & $1.57 \pm 0.029$ \\
Control & $0.97 \pm 0.020 \mathrm{a}^{* * *}$ & $2.22 \pm 0.059 \mathrm{a}^{* * *}$ & $1.16 \pm 0.025 \mathrm{a}^{* * *}$ \\
Standard & $1.32 \pm 0.031 \mathrm{a}^{* * *} \mathrm{~b}^{* *}$ & $3.92 \pm 0.039 \mathrm{a}^{* *} \mathrm{~b}^{* * *}$ & $2.00 \pm 0.013 \mathrm{a}^{* * *} \mathrm{~b}^{* * *}$ \\
Kunjad & $1.06 \pm 0.013 \mathrm{a}^{* * *} \mathrm{~b}^{* * *} \mathrm{c}^{* * *}$ & $2.96 \pm 0.044(\mathrm{a}, \mathrm{b}, \mathrm{c})^{* * *}$ & $1.33 \pm 0.025 \mathrm{a}^{* *} \mathrm{~b}^{* * *}$ \\
\hline
\end{tabular}

*The results are expressed in term of units of Catalase activity per ml.

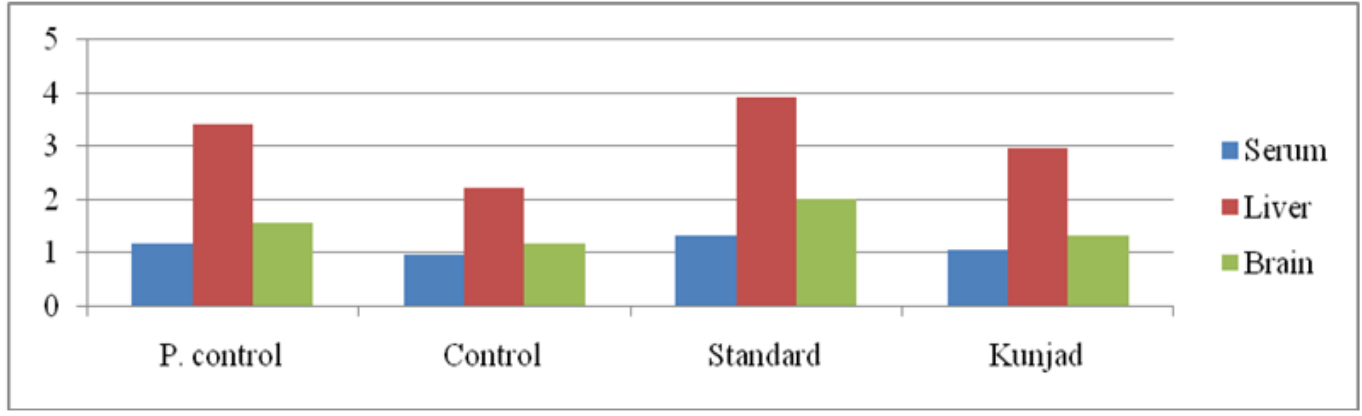

Fig. 2: Catalase activity in serum, liver and brain $(\mathrm{U} / \mathrm{ml})$

Table 3: Effect of hydro-alcohlic extract of Kunjad (Sesamum indicum) on the activity of Glutathione reductase (GR) in high fat diet induced rats, in serum, liver and brain

\begin{tabular}{llll}
\hline \multicolumn{2}{l}{ Glutathione reductase $(\mathbf{U} / \mathbf{l})^{*}$} & Liver & \\
\hline Groups & Serum & $4.37 \pm 0.153$ & Brain \\
Plain control & $2.73 \pm 0.061$ & $3.22 \pm 0.147 \mathrm{a}^{* * *}$ & $3.64 \pm 0.066$ \\
Control & $1.66 \pm 0.061 \mathrm{a}^{* * *}$ & $5.38 \pm 0.188 \mathrm{a}^{* * *} \mathrm{~b}^{* * *}$ & $2.60 \pm 0.148 \mathrm{a}^{* * *}$ \\
Standard & $3.21 \pm 0.053 \mathrm{a}^{* * *} \mathrm{~b}^{* * *}$ & $4.21 \pm 0.027 \mathrm{a}^{* * *} \mathrm{c}^{* * *}$ & $4.44 \pm 0.232 \mathrm{a}^{* * *} \mathrm{~b}^{* * *}$ \\
Kunjad & $3.04 \pm 0.044 \mathrm{a}^{* * *} \mathrm{~b}^{* * *}$ & $3.72 \pm 0.035 \mathrm{a}^{* *} \mathrm{c}^{* *}$ & \\
\hline
\end{tabular}

*The 1 Unit (U) of GR will catalyze the conversion of $1 \mu$ mole of GSSG to $2 \mu$ mole GSH per min at pH 7.6. 


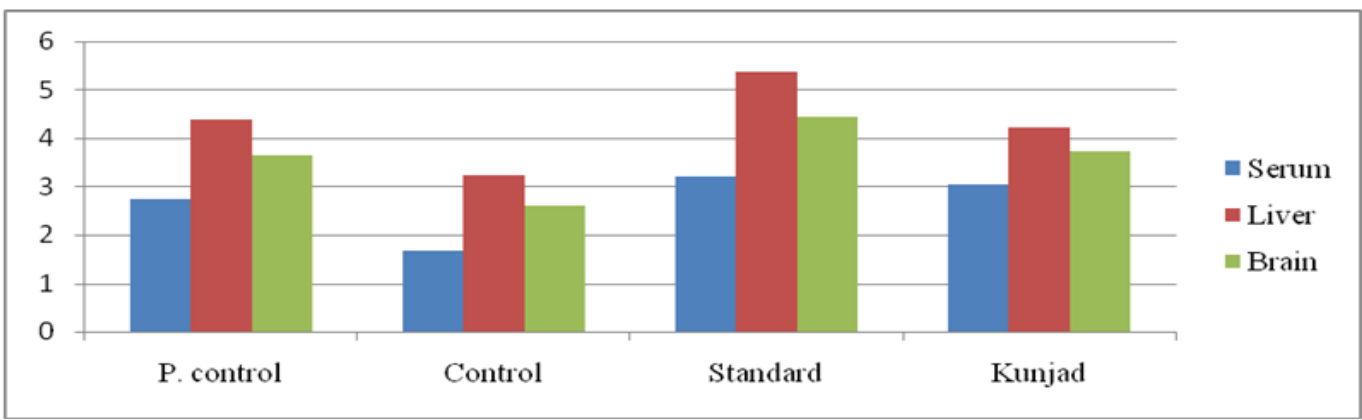

Fig. 3: Glutathione reductase (GR) activity in serum, liver and brain $(\mathrm{U} / \mathrm{ml})$

Table 4: Effect of hydro-alcohlic extract of kunjad (Sesamum indicum) on the activity of lipid peroxidation in high fat diet induced rats, in serum, liver and brain

\begin{tabular}{llll}
\hline Lipid peroxidation (TBARS) $\boldsymbol{\mu M}$ MDA $(\boldsymbol{\mu M}=\boldsymbol{\mu m o l e} / \mathbf{l i t e r}=\mathbf{n m o l e} / \mathbf{m l})$ & Liver \\
\hline Groups & Serum & $5.28 \pm 0.05$ & Brain \\
Plain control & $3.05 \pm 0.03$ & $6.68 \pm 0.11 \mathrm{~b}^{* * *}$ & $5.87 \pm 0.06$ \\
Control & $4.63 \pm 0.06 \mathrm{~b}^{* * *}$ & $4.38 \pm 0.08(\mathrm{a}, \mathrm{b})^{* * *}$ & $7.96 \pm 0.03 \mathrm{~b}^{* * *}$ \\
Standard & $2.65 \pm 0.12 \mathrm{a}^{* * *} \mathrm{~b}^{* *}$ & $5.78 \pm 0.07 \mathrm{a}^{* * *} \mathrm{~b}^{*}$ & $5.47 \pm 0.09(\mathrm{a}, \mathrm{b})^{* * *}$ \\
Kunjad & $3.45 \pm 0.03 \mathrm{a}^{* * *}$ & $6.44 \pm 0.06 \mathrm{a}^{* * *}$ & \\
\hline
\end{tabular}

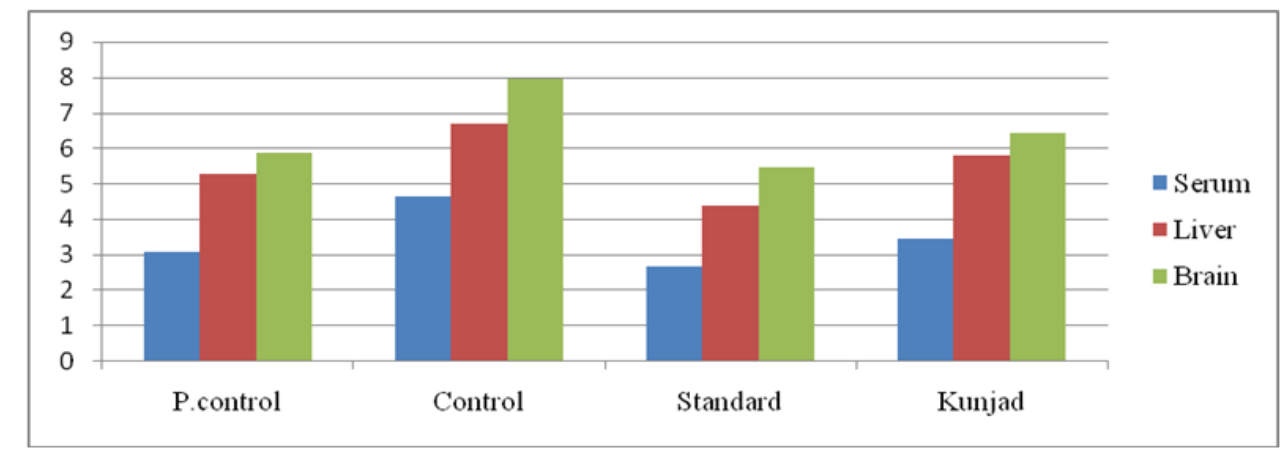

Fig. 4: Lipid peroxidation (TBARS) in serum, liver and brain ( $\mu$ M MDA)

Table 5: Effect of test drugs on lipid profile in high fat diet induced rats $(\operatorname{mean} \pm \mathrm{SE})$

\begin{tabular}{|c|c|c|c|c|c|c|c|}
\hline \multicolumn{8}{|c|}{ Lipid profile (mg/dl) } \\
\hline Group & $\begin{array}{l}\text { Total cholesterol } \\
\text { mg/dl }\end{array}$ & $\begin{array}{l}\text { Triglyceride } \\
(\mathrm{mg} / \mathrm{dl})\end{array}$ & HDL (mg/dl & LDL (mg/dl & VLDL (mg/dl) & $\begin{array}{l}\text { HDL: } \\
\text { LDL }\end{array}$ & $\begin{array}{l}\text { Atherogenic } \\
\text { Index of Plasma }\end{array}$ \\
\hline $\begin{array}{l}\text { Group I P. } \\
\text { control }\end{array}$ & $90.87 \pm 0.98$ & $159.18 \pm 2.69$ & $28.2 \pm 0.77$ & $33.74 \pm 1.20$ & $30.75 \pm 0.56$ & $0.83 \pm 0.02$ & 0.751 \\
\hline $\begin{array}{l}\text { Group II } \\
\text { Control }\end{array}$ & $104.74 \pm 0.66 \mathrm{a}^{* * *}$ & $185.67 \pm 2.45 \mathrm{a}^{* * *}$ & $24.11 \pm 1.13 \mathrm{a}^{* * *}$ & $44.59 \pm 1.19 \mathrm{a}^{*}$ & $36.07 \pm 0.79 \mathrm{a}^{* * *}$ & $0.53 \pm 0.01$ & 0.886 \\
\hline $\begin{array}{l}\text { Group III } \\
\text { Standard }\end{array}$ & $96.12 \pm 1.67 \mathrm{a}^{*}$ & $\begin{array}{l}173.18 \pm 2.47 \mathrm{a}^{* * *} \\
\mathrm{~b}^{* * *}\end{array}$ & $\begin{array}{l}28.73 \pm 0.55 \\
a^{* * *} b^{* * *}\end{array}$ & $32.62 \pm 1.87 \mathrm{a}^{* *}$ & $34.63 \pm 0.40 \mathrm{~b}^{* * *}$ & $0.89 \pm 0.05$ & 0.780 \\
\hline $\begin{array}{l}\text { Group IV } \\
\text { Kunjad }\end{array}$ & $98.24 \pm 1.58 \mathrm{a}^{*}$ & $178.00 \pm 1.14 b^{* * *} a^{*}$ & $\begin{array}{l}27.58 \pm 0.77 \mathrm{a}^{* * *} \\
\mathrm{~b}^{* *} \mathrm{c}^{* * *}\end{array}$ & $35.01 \pm 1.58 \mathrm{a}^{*}$ & $35.70 \pm 0.22 \mathrm{~b}^{* * *}$ & $0.78 \pm 0.03$ & 0.809 \\
\hline
\end{tabular}

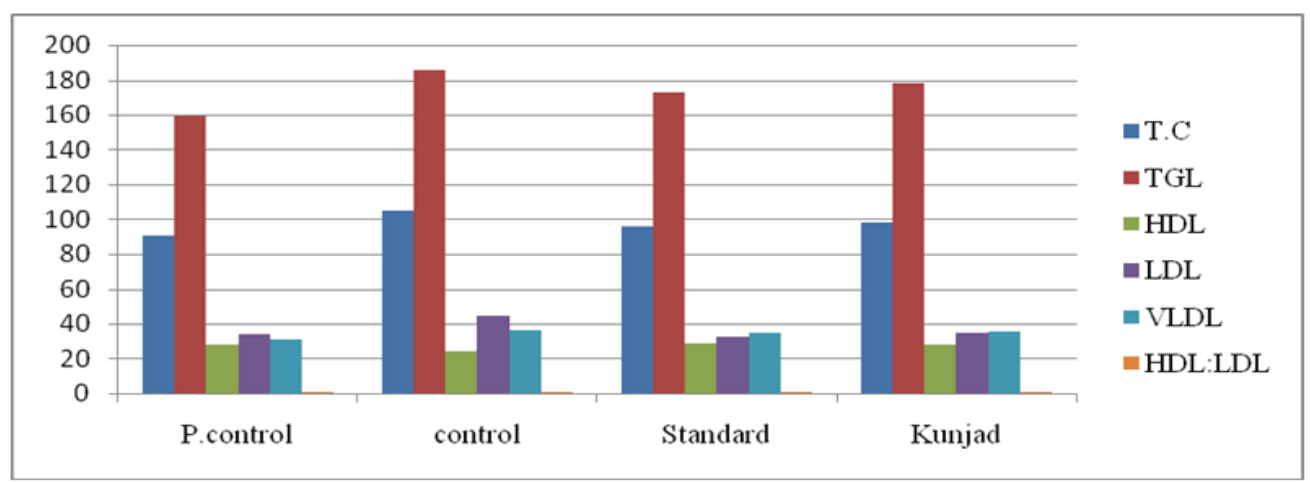

Fig. 5: Effects of test drugs on lipid profile 


\section{DISCUSSION}

The present study was evaluate the potential effects of $50 \%$ ethanolic, extract of Sesamum indicum on antioxidant status in high fat diet induced rats. The above findings show that Sesamum indicum produce a striking increase in the activity of SOD in all the 3 samples studied viz liver, brain and the serum, which is greater than the SOD activity in the plain control group. Superoxides dismutase is one of the most early and fundamental means of combating the excess ROS, by converting the superoxide ion into the relatively, less reactive oxygen and hydrogen peroxides and thus form a crucial part of the cellular antioxidant defense mechanism [25], 20 $2^{-*}+2 \mathrm{H}^{+}+\mathrm{SOD} \rightarrow$ $\mathrm{H}_{2} \mathrm{O}_{2}+\mathrm{O}_{2}$ the superoxide ion is itself reactive and may cause oxidative damage, but its harmfulness lies mainly in its being the progenitor of the more reactive and dangerous hydroxyl radical [26]. Therefore, the striking increase in SOD activity indicates that the test drugs oppose the oxidative damage at an early and crucial point by preventing the generation of one of the most reactive and dangerous oxidative group. Catalase is an ubiquitous antioxidant enzyme that is present in most aerobic cells. Catalase is involved in the detoxification of hydrogen peroxide $\left(\mathrm{H}_{2} \mathrm{O}_{2}\right)$, a reactive oxygen species (ROS), which is a toxic product of both normal aerobic metabolism and pathogenic ROS production. The catalase completes the task initiated by SOD by converting less reactive $\mathrm{H}_{2} \mathrm{O}_{2}$, produced by SOD, into two molecules of water and harmless molecular oxygen [27]. The test drugs produce a striking increase in catalase activity along with that in SOD activity, show that they very effectively prevent the generation of ROS and hence, the antioxidant activity is likely to be strong, comprehensive and complete, due to effective prevention and blockade of ROS generation will protect all biomolecules. Thus, the present study shows that MDA concentration is significantly, increased in the high fat diet control group. Malondialdehyde (MDA) is one of the many products of lipid peroxidation caused by reactive oxygen species (ROS), therefore, the increase in MDA concentration indicate an increase in Lipid peroxidation. Malondialdehyde (MDA) is a naturally occurring product of lipid peroxidation, lipid peroxidation is a well-established mechanism of cellular injury in both plants and animals and is used as an indicator of oxidative stress in cells and tissues $[28,29]$. During lipid oxidation, malanoaldehyde (MDA) can react with the free amino group of proteins, phospholipids, and nucleic acids damaging their structure and functions. Increased levels of lipid oxidation products are associated with diabetes and atherosclerosis $[30,31]$. Oxidative stress, i.e. induced generation of ROS that cannot be fully antagonized, by physiological antioxidants, results in oxidative damage to all biomolecules, however, lipid damage is the most important and takes the form of lipid peroxidation. The significant decrease in MDA concentration shown in the standard group, administered with standard antioxidant agent Vit E $(\alpha-$ tocopherol acetate), indicate the integrity and validity of our experimental procedure by showing the expected protective effect of Vit $\mathrm{E}$ against Lipid peroxidation. So the increase in lipid peroxidation and decreases in SOD, Catalase and GR concentration shows that the high fat diet induced in rats successfully, causes oxidative stress and damage. Therefore, lipid rich diets also capable of generating ROS because of antioxidant enzymes they can alter oxygen metabolism. Upon the increase of adipose tissue, the activity of antioxidant enzymes such, as SOD, CAT and glutathione peroxides (GPx) was found to be significantly diminished [32], finally, high ROS production and the decrease in antioxidant capacity leads to various abnormalities especially, endothelial dysfunction, in a study [33], showed that a diet high in fat and carbohydrates induces a significant increase in oxidative stress and inflammation in person with obesity. Therefore, we observed a significant reduction in antioxidant enzymes such as SOD, CAT, activity and glutathione level in almost all tissue of high fat induced rats compared with non-fat animals. On the other hand non-enzymatic oxidative stress parameters lipid peroxidation marker MDA level increased in these tissues. Several studies have been show, that high fat diet induced decrease antioxidant capacity in different organs. In present study the significant decrease in MDA concentration and significantly increase in other antioxidant parameters shown in the standard group, administered with standard antioxidant agent Vit E ( $\alpha$ tocopherol acetate), indicates the integrity and validity of our experimental procedure by showing the expected protective effects of Vit $\mathrm{E}$ against all antioxidant parameters.

\section{CONCLUSION}

In the present study showed that the $50 \%$ ethanolic extract of Sesamum indicum shown to exert its antioxidant effect mainly by ROS generation blockade due to increased SOD and catalase and Glutathion reductase activity. However, Lipid peroxidation also plays an important role in its antioxidant activity. Based on this study we conclude that ethanolic extract of Sesamum indicum have significant antioxidant activities as compared with alpha tocopherol acetate (Standard).

\section{ACKNOWLEDGEMENT}

The author is grateful to Department of Biochemistry, Faculty of Life Science AMU, Aligarh, for approving the study by Departmental Institutional Animal Ethics Committee (IAEC), also the author would like to thank Mr. Sehzad AMU, Aligarh, for helping in animal handling.

\section{AUTHORS CONTRIBUTIONS}

All the author have contributed equally.

\section{CONFLICT OF INTERESTS}

We declare that we have no conflict of interest.

\section{REFERENCES}

1. Pham Huy LA, H He, Pham Huy C. Free radicals, antioxidants in disease and health. Int J Biomed Sci 2008;4:89-96.

2. Chopra IC, Handa KL, Kapur LD. Indigenous drugs of India. $2^{\text {nd }}$ ed. U. N. Dhur and Sons Private Limited, 15, Bankim Chatterjee Street Calcutta-12; 1958. p. 569.

3. Bhattacharjee SK. Hand book of medicinal plants. $4^{\text {th }}$ edn. Pointer Publishers, Jaipur; 2004. p. 320.

4. Nadkarni KM. Indian materia medica. $3^{\text {rd }}$ ed. Popular Book Depot Bombay 7, Dhootapapeshwar Prkaashan Ltd; 1982. p. 1126-9.

5. Evans WC. Trease and evans pharmacognosy $16^{\text {th }}$ ed. Saunders Elsevier Edinburgh London New York Philadelphia St Louis Sydney Toronto; 2009. p. 190.

6. Ghani MN. Khazayinul Advia. $1^{\text {st }}$ ed. Central council for Research In Unani Medicine, Ministry of Health and Family Welfare, Govt. of India, New Delhi; 2010. p. 180-5.

7. Khory RN, Katarak NN. Materia medica of India and therapeutics. $3^{\text {rd }}$ Reprint ed. Pub. Neeraj Publishing House Delhi-110052; 1993. p. 462.

8. Namiki M. Nutraceutical functions of sesame: a review. Crit Rev Food Sci Nutr 2007;47:651-73.

9. Hirose N, Inoue T, Nishihara K, Sugano M, Akimoto K, Shimizu $\mathrm{S}$, et al. Inhibition of cholesterol absorption and synthesis in rats by sesamin. J Lipid Res 1991;32:629-38.

10. Bedigian D, Harlan JR. Evidence for cultivation of sesame in the ancient world. Econ Bot 1986;40:137-54.

11. Shahidi F, Liyana Pathirana CM, Wall D. Antioxidant activity of white and black sesame seeds and their hull fractions. Food Chem 2006;99:478-83.

12. Liu Z, Saarinen NM, Thompson LU. Sesamin is one of the major precursors of mammalian lignans in sesame seed (Sesamum indicum) as observed in vitro and in rats. J Nutr 2006;136:90612.

13. Ghafoorunissa, Hemalatha S, Rao MV. Sesame lignans enhance antioxidant activity of vitamin $\mathrm{E}$ in lipid peroxidation systems. Mol Cell Biochem 2004;262:195-202.

14. Costa FT, Neto SM, Bloch C, Franco OL. Susceptibility of human pathogenic bacteria to antimicrobial peptides from sesame kernels. Curr Microbiol 2007;55:162-6.

15. Yokota T, Matsuzaki Y, Koyama M, Hitomi T, Kawanaka M, Enoki Konishi M. Sesamin, a lignan of sesame, downregulates cyclin D1 protein expression in human tumor cells. Cancer Sci 2007;98:1447-53.

16. Visavadiya NP, Narasimhacharya AV. Sesame as a hypocholesteraemic and antioxidant dietary component. Food Chem Toxicol 2008;46:1889-95. 
17. Ashakumary L, Rouyer I, Takahashi Y, Ide T, Fukuda N, Aoyama $\mathrm{T}$. Sesamin, a sesame lignan, is a potent inducer of hepatic fatty acid oxidation in the rat. Metabolism 1999;48:1303-13.

18. Nakano D, Kurumazuka D, Nagai Y, Nishiyama A, Kiso Y, Matsumura Y. Dietary sesamin suppresses aortic NADPH oxidase in DOCA salt hypertensive rats. Clin Exp Pharmacol Physiol 2008;35:324-26.

19. Lee CC, Chen PR, Lin S, Tsai SC, Wang BW, Chen WW. Sesamin induces nitric oxide and decreases endothelin-1 production in HUVECs: possible implications for its antihypertensive effect. J Hypertens 2004;22:2329-38.

20. Kirtikar KR, Basu BD. Indian medicinal plants. Pub. International Book Distributers, Dehradun; 1995. p. 1858-61.

21. Dymock W, Warden CJH, Hooper D, Pharmacographia Indica. A history of the principal drugs. The institute of health and tibbi research, hamdard national foundation, Pakistan; 1972. p. 337-8.

22. Freirich EJ, Gehan EA, Rall DP, Schmidt LH, Skipper HE Quantitative comparison of toxicity of anti ulceragents in mouse, rat, hamster, dog, monkey and man. Cancer Chemother Rep 1966;50:219-44.

23. Kimuru Y, Rhminani H, Okuola H. Effect of extract of oyster on lipid metabolism in rats. J Ethnopharmacol 1998;59:117-23.

24. Friedewald WT, Levy RI, Fredrickson DS. Estimation of the concentration of low-density lipoprotein cholesterol in plasma, without use of the preparative ultracentrifuge. Clin Chem 1972;18:499-502.
25. Malstrom B, Andreasson L, Reinhammer B. In: The enzymes. Boyer P. editor XIIB. Academic Press: New York; 1975. p. 533.

26. Fridovich I. Biological aspects of Superoxide radical and superoxide dismutase. Biochemical and Medical Aspects of Active Oxygen. Asada K, Hayaish O. Editor. Baltimore: University Park Press; 1977. p. 171-6.

27. Aebi HE. Catalase in vivo. Methods in enzymology. L Packer. editor. N. York: Academic Press; 1884. p. 121.

28. Yagi K. Simple assay for the level of total lipid peroxidation in serum or plasma metods in molecular. Biology 1998;108:1016.

29. Armstrong D, Browne R. A systemic approach to laboratory technology, clinical correlation and antioxidant therapy. Free Radicals Diagnostic Med 1994;366:43-58.

30. Spiteller G. Lipid peroxidation in aging and age-dependent diseases. Exp Geront 2001;36:1425-57.

31. Evans P, Halliwell B. Free radicals and hearing, causes, consequence and criteria. Ann N Y Acad Sci 1999;884:1940.

32. Noeman SA, Hamooda HE. Biomedical study of oxidative stress markers in liver, kidney and heart of high fat diet induced obesity in rats. Diabetol Metab Syndrome 2011;3:1-17.

33. Patel C, Ghanim H, Ravishankar S, Sia CL, Viswanathan P, Mohanty $\mathrm{P}$, et al. Prolonged reactive oxygen species generation and nuclear factor-kappaB activation after a high-fat highcarbohydrates meal in the obese. J Clin Endocrinol Metab 2007;92:4476-9. 